\title{
Planning and Restoration of Environmental Values in Nigeria Dysfunctional Societies
}

\author{
${ }^{1}$ Basorun, J. O. and ${ }^{2}$ Ayeni, D.A
}

\begin{abstract}
:
Urban centers in Nigeria are becoming dysfunctional - a situation that threatens our environmental values. This study, examines the pattern, process and problems of these societies which experience rapid urban development pressure on account of high population growth and decentralization of governance in the form of states and local government creations. The study adopts extensive review of literature and findings reveal that Nigeria records very high level of urbanization and pollution, lacks effective cultural and physical planning policies, mismanages its urban open spaces, without adequate personnel to plan and organize the urban environments. Recommendations were made on ways of restoring these environmental values through effective planning of urban centers in Nigeria.
\end{abstract}

Keywords: Environment, Nigeria, Planning, Urban centre, values

\section{Introduction}

Values are broad preferences that express what we perceive to be fundamental about life. A value expresses, principally, the social requirement and the very interest of generally formed and recognized injunctions and evaluation which are stable in nature, and are strengthened and supported by moral force of life (Nicholas and Carlos, 2002). It guides human activities in choosing means to an end and making decisions (Ogoko and Albert, 2006). In most cases, it represents standard rule that dictates what human beings should and should not do under a given circumstance. Generally, values serve as codes of conduct that govern peoples' actions, thus, are essential for society maintenance.

A society is broadly a group of people who share a common culture and occupy a particular territorial area, with the feeling of constituting a unified and distinct entity. In this perspective, societal values are ideals; ways of life, and most times,

${ }^{1}$ Department of Urban and Regional Planning,

${ }^{2}$ Department of Architecture,

School of Environmental Technology, Federal University of Technology, Akure, Nigeria. 
the expectations of the citizens within any society with regards to the utilization of resource, man's interaction with the ecosystem, and sustainability of the environment. They are basic conceptions of the desirable or "expression of prediction emulated by others, and ultimately used by humans to acquaint them and rationalize their choices (Sillars and Gronback, 2011).

In Nigeria, the society and the physical environment fail to reflect much of this reality. The value system is eroding in the face of threatening alien values of colonialism. Majority of our societies today, are driven here and there by vicissitudes of life; compelled to use land solely by our urges and passions for revenue base, recognition and power with little consideration for environmental sanity. We seem to be living in a world devoid of values, thus, prognosticating our conscious, purposeful and dynamic existence. Restoring societal values at this critical period is expedient to bring sanity to the society and keep it functioning (Shilling, 2007). The environmental planner is required to make impact in stabilizing the various activities across space to improve the quality of our societal value through efficient planning.

\section{Environmental Values}

The environment is the totality of all external and physical or social resources available to the satisfaction of human needs. It is where man resides and all his activities take place. Invariably, the environments of our various societies constitute capital assets which unlike other forms of capital are poorly understood, scarcely monitored and in most cases undergoing rapid degradation. It is a common knowledge that "environmental values are products of social constructions" (Hannigan, 2006), needed by people in situation that concern environmental questions (Stern, 2000a). Environmental planners persistently argue that we must consider our daily approaches to decision-making on what is valuable about the environment. The dominating tendency of man to use the environment for his benefit often leads to environmental chaos which necessitates proper planning and management concepts. Certain principle or guidelines are essentially passed on to future generations as cultural value. These guidelines now constitute widely held beliefs about some activities, relationships, feelings and goals that are important to the community well-being. They are seen as standards of importance to the society (Shilling, 2007) created for carrying out the necessary tasks of collective life.

Preference in the environment and good landscape is one of the cardinal aesthetic virtues of modern society. Traditional landscape makes reference to the notion of "homelands" where the landscape is a product of the people living and working on the land. With the focal shift towards urban and global arenas, a multitude of postmodern landscape is evident and include, gardens/parks, 
playing ground, sporting facilities for recreation to renew ones health and spirits of enjoyment and relaxation. The difference between traditional and new (postmodern) landscape resides in their dynamics, both in speed and scale, as well as the changing perceptions, values and behaviors of their users. (Antrop, 2005:25).

The various types of roads and other communication channels that allow direct accessibility to plots and other services in the environment are of immense value. They do not only encourage movement around neighborhoods, but also provide accessibility with minimum cost possible. Indeed one of the major functions of the capital structure of any human settlement is to facilitate the mobility and circulation of people and goods within the environment (Mabogunje, 2008).

Man desires good environmental sanitations devoid of air, water and land pollution, slum area and diseases that claim lives. This suggests that the entire human environment should be free from toxic chemicals resulting from industrial gas flaring, global warming, waste and garbage mismanagement and oil spillage, which are dangerous to its habitats. Examples are the SARS disease which scares the Chinese and the Southeast Asians, the bird flu in Thailand and the red tide of rivers that killed many sea creatures around the world. Also close to our mind is the oil spillage and gas flaring in the oil producing areas of Nigeria.

The physical manipulation of the human environment in terms of its spatial organization sets forth a series of connected qualitative effects in the provision of essential infrastructure such as street furniture, main drainage, sewerage, electricity, water and other sanitary facilities. Value is often attached to a well planned society where land use proposals including infrastructural facilities and social services allow for action area development policies, and standard for order, functionality and aesthetics. In a desperate effort to restore these values, environmental management appears a veritable tool. This prescribes an articulated analytical framework and logical structure which facilitates better understanding of the dynamism of environmental issues that help in evolving guidelines or strategies for intervention (Taiwo and Busari, 1979). Thus, the main objective of this study is to investigate the loss of environmental values in Nigeria and the need for restoration for effective physical development.

\section{Study Area and Methodology}

The federal Republic of Nigeria is made up of 36 states and the Federal Capital Territory, Abuja. The country lies between Latitude $10^{\circ} 00^{\prime} \mathrm{N}$ of the Equator and Longitude $8^{0} 00^{\prime}$ East of the Greenwich Meridian and bounded in the West by the Republic of Benin; to the East by Cameroon and Chad Republic; to the North by Niger and to the South by the Gulf of Guinea as show 
in Figure 1. Nigeria has a total area of 923,768 Square Kilometer and a population of about 167Million (Esu, 2009; Olokor, 2012; World Bank, 2012; Map of World, 2012, Greenwich Mean Time, 2012).

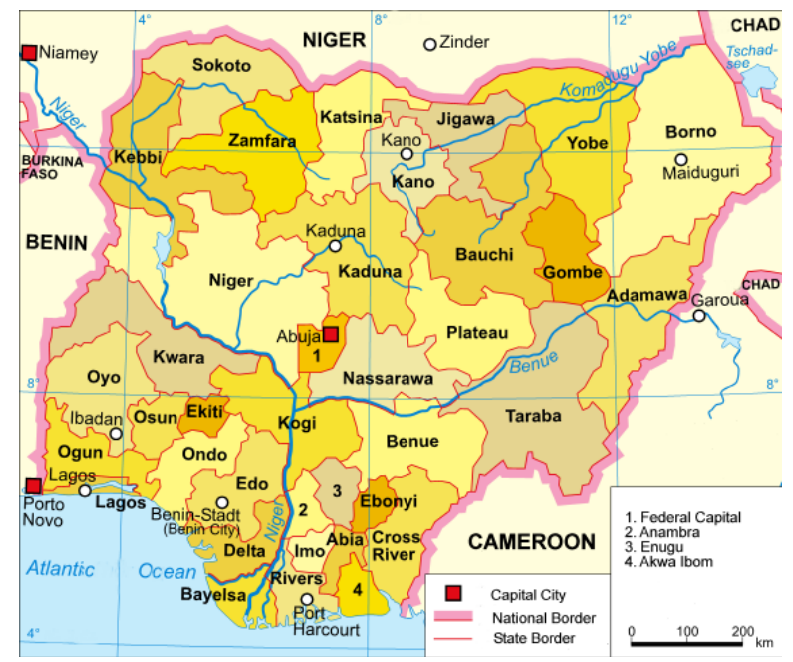

Figure 1. Map of Nigeria and the Constituent States

Source: http://upload.wikimedia.org/wikipedia/commons/d/d2/Nigeria political.png The study is based on the planning and restoration of environmental values which are currently lacking in Nigeria and adopted the qualitative research approach through the review of relevant literature in order to contextualize current research in the field of study. Data were sourced from published material such as books, journal articles, as well as from the internet amongst others. These gave an in depth knowledge on environmental values, planning, the physical environment and planning policies in Nigeria.

\section{The Challenges of Nigeria Dysfunctional Societies}

Up till 1950, there were only eight (8) cities globally with population of 5 million and more (Montgomery, et al, 2004:85). Among these were New York, London and Tokyo that were the world's major maga-cities, with population of 12.3 million, 8.7 million and 6.9 million respectively. Since the $1950 \mathrm{~s}$, however, most of the remarkable growth in the size of cities has been taking place in developing countries including Nigeria. The growth of population in Nigeria, for instance, escalated from 31.6 million in 1953 to over 140 million in 2001 with more than fourfold increase within 50 years (Mabogunje, 2008).

This growth is precipitated principally on the country's level of urbanization, that is, the share of the country's population living in urban areas; a process which increased steadily throughout the $20^{\text {th }}$ Century because of the large pool of 
potential migrants to the cities living in the country-side (Brokerhoff, 2000). The creation of states since 1967, has re-directed rural-urban migration streams to many of the new State capital, majority of which are bestowed with the rudimentary capacity to absorb modern industrial and commercial establishments. The complexity of these movements along with the complexity of the social, cultural, economic, political and administrative urban functions render these societies dysfunctional and pose grave challenges to environmental values.

In tracing the locale history and culture in an urban set up, attention is often directed to the city centre because it is the storehouse of historical and cultural heritage (Seralgeldin, 1997). Effective cultural policies hardly exist to preserve cultural heritage in Nigeria cities. The failure of the government to willingly allocate resources to this sector has stemmed from the belief that "the past belongs to history" (Goebert, 1997). As argued by Quezon (2002), "the city is aesthetically the showplace of the nation where thousands of people visit as epitomes of cultures"; rich in cultural artifacts, historic buildings, and traditional architecture.

The poor quality of the Nigeria urban environment has been attributed partly to the inadequate, misuse and mis-management of the urban open spaces. This, in the opinion of Fadamiro (2002a, 2002c) has exerted a major strain on the physical outlook of the environment and a negative effect on the welfare and productivity of the residents. The road network in many parts of the city are poorly articulated, reducing the traffic routes options available to motorists. Efficient flow of traffic is often interrupted by accidents especially where the street designs is of grid-iron pattern. This problem is aggravated by the lack of coordination between federal, state and local council road networks which result in the existence of sharp break in road quality and maintenance standard (Mabogunje, 2008).

One apparently growing environmental challenge in the urban societies is the increasing incidence of air and noise pollution. The most ambient air pollution comes from the combustion of fossils fuels in all motorized vehicles and industrials machines. The various emissions tend to generate photochemical pollutants, lead and carbon monoxide. High occupancy ratios ranging from 4 5 persons per room is obvious; majority of the households still depend on the crude traditional means of heating; substantial proportion of houses lack arrangements for refuse and sewage disposal systems to compound the sanitation situations of city neighborhoods (Basorun, 2003).

Creation of convenient environment, conducive to good health and peoples' social and economic development is a function of the Master Plan. Many Master plans have been prepared for many cities in Nigeria, but most of them have failed to work because of the improper and uncoordinated data underlying their 
preparation (Olanrewaju, 2004). Looking at the institutional problems of physical planning in Nigeria, minimal benefits are received from the specialist skills of Professional Town Planners. By 1987, barely 500 Professional Town Planners were registered. This figure slightly increased beyond 2000 in 2004 to 2068 in 2010 . There is, therefore, a paucity of trained professionals to plan and organize the multitude of cities (Fasakin, 2006). Aside from these inadequate personnel, lack of resources (fund and patrol vehicles) to monitor development have contributed more to the problems with the attendant erection of illegal structures, arbitrary change of use and encroachment on road reserves in the societies.

\section{Urbanization and the Physical Planning Policies in Nigeria}

The problems associated with urbanization especially its effects on the Nigeria's built environment have been widely acknowledged by various researchers (Oduwaye, 2009; Dimuna and Omatsone, 2010; Dimuna, 2011; Olujimi, 2011; Ayeni, 2012; Babalola, 2012) to characterize chaos, deterioration, decay, poor quality and unplanned developments. Conversely, these have affected environmental planning. Urbanization as defined by Olujimi (2011) is 'the process by which urban population increases in absolute number and in proportion to rural population'; and simply a process of population concentration (Jiboye, 2011; Tisdale, 2012). The overwhelming increase has caused many of the urban areas in Nigeria to be in shabby states and insanitary conditions.

As population continues to increase at an alarming rate in urban areas in developing countries, unplanned, informal settlements and slums continue to grow (Aluko, 2010) which adversely give rise to unpleasant living environment. As argued by Williams (2000); Alam et al (2006), this also leads to inevitable congestion which causes environmental hazards and degradation. Currently, Nigeria is experiencing its fair share of urbanization (Adediran et al, 2012) and rated among urban areas with lowest livability index in the world (Daramola, and Ibem, 2010). And as a developing country, is not left out of the environmental problems that come with urbanization; as these are very much evident in the urban areas. The problems as noted by Olujimi (2011) are associated with diversity of functions where various occupations, industries and services are represented; and have caused different environmental damages such as ecological disturbances, destruction of flora and fauna, air, water and land pollution, landscape degradation, environmental decay, overcrowding, congestion, as well as crime and violence (Daramola and Ibem (2010; Jiboye, 2011; Gutti, Aji and Magaji, 2012). 
Contrary to the situation in developed countries, urbanization process as observed by Aluko (2010); Jiboye (2011) was as a result of rapid industrialization which subsequently transformed the cities, whereas in Nigeria, it is a consequence of 'push' from the rural areas and the 'pull' to the town, which have posed the challenge of diverse socio-economic, cultural and environmental problems and require effective and good governance in order for the problems to be addressed.

Many factors have been traced to be responsible for the poor state of the environment in Nigeria. The major one is the poor environmental management practices which have lead to poor quality of the environment in the urban areas (Daramola and Ibem, 2010). With the rapid rate of urbanization and constant demand for land for different purposes, Arigbola (2008) argues that adequate planning and control is needed to ensure harmonious development.

\subsection{Planning and the Physical Environment}

Planning as averred by Olajuyigbe and Rotawa (2011) is the 'art and science of organizing the use of land for greater good of the society,' otherwise expressed as physical planning. Land use planning on the other hand involves development of land use issues, indicating appropriate development in areas of special environmental concern (Williams, 2000). Land use planning as noted by Ogu (2010) has an impact on the efficiency of economic and social activities and also on the physical development of a city. It can therefore be suggested that it informs the quality of the environment; and should be managed by built environment professionals at the national, state, local government levels. However, in Nigeria, many of the physical planning policies are not effectively practiced.

Physical planning is a conscious but comprehensive approach to the orderly and healthy use of the natural environment as well as management of human settlements systematically. The aim is to organize the spatial structure of activities (land uses) within cities with the objective of ensuring that results are in some way better than would have been the case without such planning (Mabogunje, 2005). A community is planned for growth while preserving the natural and historic nature of its environment (Walter, 2007). With physical planning attempts are made to achieve the best possible spatial coordination of different human activities for the enhancement of people's quality of life.

As observed by Arigbola (2008); Alabi and Akinbode (2010); Olajuyigbe and Rotawa (2011), physical planning policy provisions which includes land use Act of 1978, Urban and Regional planning Act 1992, Urban Development Policy 1992 and the Housing and Urban Development Policy 2002, have evolved to improve the urban physical environment. However, many urban areas are still faced with series of ineffective physical planning as a result of poor 
implementation, poor funding and inadequate modern planning approaches. Unless a proper physical planning standard is set and development in urban areas monitored and guided by appropriate policies, Nigeria would continue to record poor environmental quality.

\subsection{Environmental Planning and Urban Open Spaces}

Physical environment as argued by Dimuna (2011) is an important component of the environment because the organism, individual, and the community are in direct contact with it. Environmental planning, therefore, is the art of organizing the surrounding where both living and non living organisms live for their existence. Open space on the other hand refers to undeveloped land within the boundary of a neighborhood which provides, or has the potential to provide social, environmental or economic benefits to communities (Ayeni, 2012). It is a land not built upon and may be natural or manmade (Asikogu and Asikogu, 2008); whose importance to the environment and quality of life is increasingly being recognized (Maruani and Amit-Cohen, 2007).

The situations in urban areas in Nigeria reveal the rate and pace at which growth has resulted in unplanned land use and weak development resulting in the lack of open spaces and substandard development (Omuta, 2006; Okolo and Okolei (2010). Many of the urban areas are characterized by neglect, loss, misuse and have impacted negatively on the environmental outlook with no opportunities for recreation, conservation and improved biodiversity (Okolo and Okolie, 2010). The improvement and proper functioning of these spaces will help revitalize many lost values in the Nigerian urban areas.

Olotuah and Bobadoye (2009) and Alabi (2009) observe that many Nigerian cities are characterized by inadequate, unorganized and loss of open spaces; which can be traced to the rapid rate of urbanization and the lack of proper environmental planning. Indeed, availability of open spaces is a basic need in any urban environment. It enhances livability in cities as a social amenity and serves as a yard stick for measuring environmental success of cities (Adejumo, 2012). Ayeni (2012) maintains that some functions of open spaces include serving as avenue for outdoor interactions, contact with nature, community cohesion, provides beauty and diverts attention from monotonous form of buildings in the urban areas. The urban aesthetics, visual order and character are reflected in these spaces which offer the opportunity for relaxation in order to ease out accumulated stress.

Effective environmental planning as noted by Omuta (2006) must adopt a holistic approach which recognizes the need for a comprehensive environmental planning and concentration of environmental authority. The absence and misuse, of open spaces in Nigeria need quick intervention from the government and the 
environmental planning professionals and Agencies both at the national, state and local levels to improve the quality of the environment and life of the people.

\section{Restoring the Environmental Values}

Planning is done systematically, anticipation adjustment of a part or a whole settlement, given the constraints of social, economic, political and human resources. In practical term, environment, planning and development are strongly connected with management. The linkage is made through actions meant to administer development in an institutional and financial planning system. Management is concerned with the effective utilization and coordination of resource such as capital, plants, materials and labour to achieve defined (environmental) objectives with maximum efficiency (Santrock, 2007). In the process, policies, plans and programs are set out, so that both private and public initiatives are effectively managed to give direction and control to values of the environment. This is demonstrated in a model as shown in figure 1.

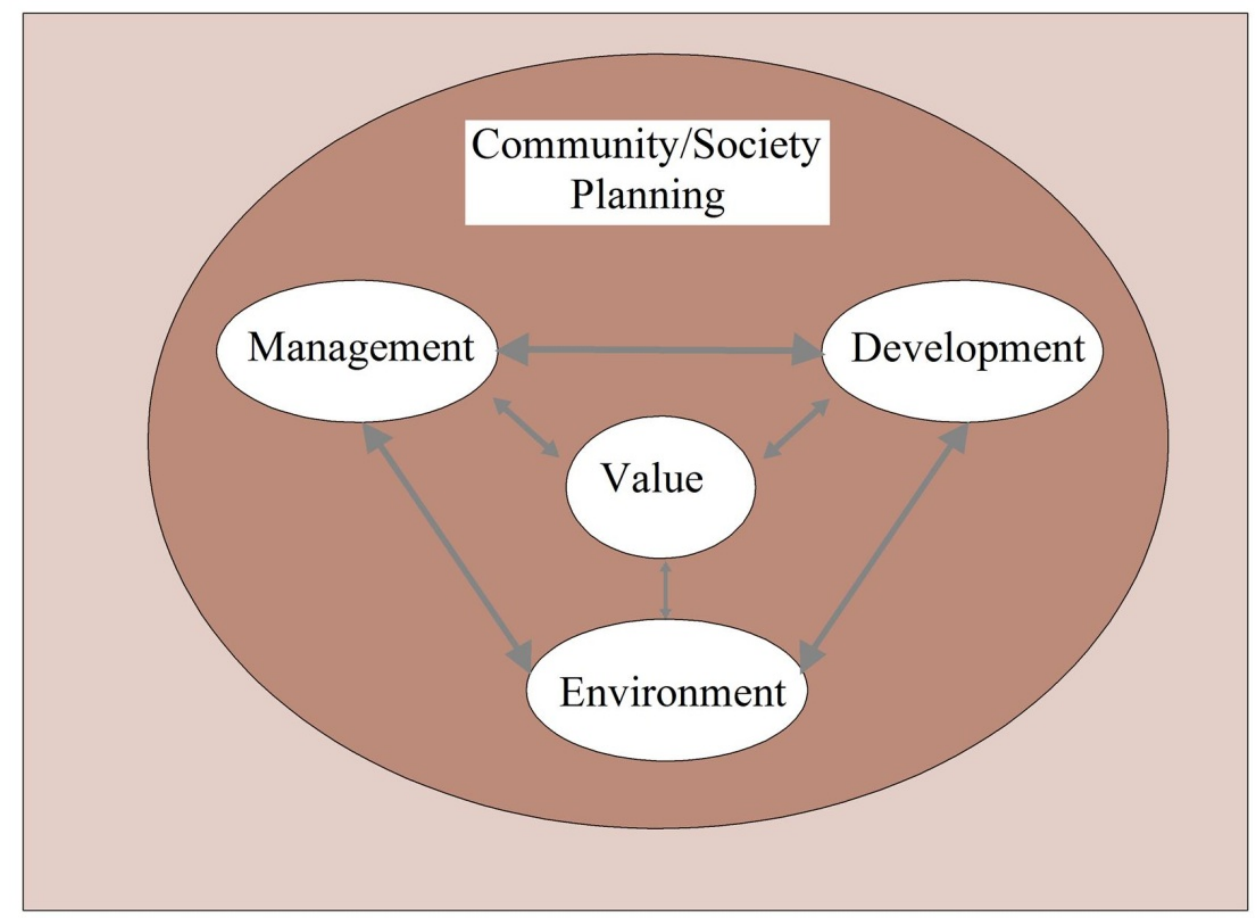

Fig. I Model showing centrality of value in Community/Society Planning

Without values, a society cannot exist. Having established clear-cut values in contemporary Nigerian societies, the basic planning tasks, therefore, include: 
(i) Directing people to follow a clear set of rules and guidelines for their actions and not to chase short-term gains at the expense of the society long-term goals that can be beneficial to all. The State Ministries of Physical Planning and Urban Development should initiate 'sustainable Master Plans' for the urban centers to create opportunities for citizens to live in better environment. The plan will aggregate and prescribe orderly physical development by providing access to houses, industries and commerce, increasing standard land allocation to industrial enterprises to raise employment opportunities and adequate space for community facilities.

(ii) The State Ministries of Environment should guide people in making appropriate development decisions in line with the laid down values. This will cover beautification and standard of housing especially in the urban centers which are unsatisfactory, poor sanitation, and destruction of vital natural resources such as soils, vegetation cover, wildlife as well as pollution through oil spillage evident in the coastal region of the country.

(iii) Educating the public through seminars, workshops, conferences, mass media, newspapers etc on ways of discovering compatible companions, places and things that support their way of living should be exclusively handled by the Local Government Councils. The priorities of societal values are embedded in the concept of Environmental Planning and Management (EPM). This strategy encourages initiation of a participatory framework (working group) to decide and mobilize on practical course of action to deal with environmental issues.

(iv) The Federal and State Governments need to create the enabling atmosphere for people to live with integrity and shun corruption, nepotism, favoritism and tribalism - "all which constitute moral decay" (Michael, 2007). This entails promotion of peace, harmony, transparent accountability, mutual respect, spirit of hard work, contentment and hospitability by government functionaries.

\section{Conclusions}

Nigeria has one of the largest annual population and urban growth rates in Africa. The cities, no doubt, play a key role in the development process as productive places that make significant contributions to national economic growth. The process of urban growth often brings with it, deterioration of the society environmental values which threaten the continued productivity of cities, the health and quality of life of its citizens. As major environmental hot spots, urgent special attention is required to restore the values we subscribe to and are 
meaningful to us. Once these values are restored, good fortune is sure to follow in the form of new opportunities, and other forms of material and psychological benefits. The study, therefore, has investigated the loss of environmental values in Nigeria arising due to the rapid rate of urbanization and inappropriate standard, and recommends that unless appropriate planning policies are provided and followed, there will be continual loss on the environmental values, which at the same time will lead the reduced quality of life of the people.

\section{References}

Adediran, O., Akintunda, A. A., Edo, A. E., Opadijo, O., \& Araroye, A. M. (2012). Impact of Urbanization and Gender on Frequency of Metabolic Syndrome among Native Abuja Settlers. Cardiovascular Disease Research, 3(3), 191-196.

Adejumo, T. (2012). Development Strategy for Sustainable PublicOpen Space System in Metropolitan Lagos. Retrieved from http://www.unilag.edu.ng/opendoc.php? Accessed on $14 / 10 / 12$

Alabi, M. O. (2009). Revitalizing Urban Public Open Spaces, through Vegetative Enclaves in Lokoja, Nigeria. Geography and Regional Planning, 2(3), 051-054.

Alabi, M. O., \& Akinbode, A. (2010). Towards Effective Physical Planning in Local Governments in Nigeria. Environmental Research Journal, 4(2), 173-176.

Alam, M. D. J. B., Alam, M. D., Rahman, M. H., Khan, S. K., \& Munna, G. M. (2006). Unplanned Urbanization: Assessment through Calculation of Environmental Degradation. Environmental Science and Technology, 3(2), 119-130.

Aluko, O. E. (2010). The Impact of Urbanization on Housing Development: the Lagos Experience, Nigeria. Ethiopian Journal of Environmental Studies and Management, 3(3), 64-74.

Antrop, M. (2005): "Why Landscapes of the past are important for the Future" Landscape and Urban Planning, 70(1-2): 21- 34.

Arigbola, A. (2008). Improving Urban Land Use Planning and Management in Nigeria. Theoretical and Empirical Researches in Urban Management, 3(9), 1-14.

Asikogu, L. O., \& Asikogu, U. A. (2008). The Imperative Open Spaces and Recreation Parks in the Master Plan of a City. Research in National Development, 6(2).

Ayeni, D. A. (2012). Towards Effective and Sustainable Use of Open Spaces in Nigeria. International Journal of Engineering Science and Technology, 4(6), 3039-3049.

Babalola, D. O. (2012). Globalization and the Built Environment, Urbanization and Sustainable Housing Development. Retrieved from www.unhabitat.covenantuniversity.edu.ng/research-Abstracts . Accessed on $15 / 10 / 12$.

Basorun, J.O. (2003): Basic Elements of Urban and Regional Planning, Akure, Shalom Publishers, 128.

Brockerhoff, M. P. (2000): “An Urbanizing World” Population Bulletin, Population References Bureau, UN.

Daramola, A., \& Ibem, E. O. (2010). Urban Environmental Problems in Nigeria: 
Implications for Sustainable Development. Sustainable Development in Africa, 12, 137-145.

Dimuna, K. O. (2011). The Social Effects of the Built Environment: A case Study of Selected Buildings in Benin City, Nigeria. Human Ecology, 34(3), 189-196.

Dimuna, K. O., \& Omatsone, M. E. O. (2010). Regeneration in the Nigeria Urban Built Environment. Human Ecology, 29(2), 141-149.

Esu B.B (2009) Tourists satisfaction with cultural tourism festival; a case study of Calabar Carnival Festival in Nigeria, International Journal of Business and Management, Vol 4 (3) pp116-125.

Fadamiro, J. A. (2002a): Open Space Concept and Evaluation in the Medium Urban Environment, A case study of Akure, Nigeria. Journal of Environmental Technology, 1(1):79-90.

Fadamiro, J. A. (2002c): Landscaping and Open Space Relationship: A Strategy for an

Effective and Sustainable Development of Urban Environment, African Journal of Social and Policy Studies, 2(1\&2): 141-147.

Fasakin, J. O. (2006): Asymmetries in Philosophy and Practice of Physical Planning in Nigeria, Inaugural lecture, Series 43, Federal University of Technology, Akure, 2006, 44.

Geobert, R. (1997): “Children Preserving their Past in Jordan” The Urban Age, 4(4).

Greenwich Mean Time (2013) Nigeria Map. Retrieved from www.greewichmeantime.com/timezone/Africa/Nigeria/map-Nigeria

Accessed on 29/1/13

Gutti, B., Aji, M. M., \& Magaji, G. (2012). Environmental Impact of Natural Resources Exploitation in Nigeria and the Way Forward. Applied Technology in Environmental Sanitation, 2(2), 95-102.

Hannigan, J. A. (2006): Environmental Sociology (2nd Ed.), New York, Routledge.

Jiboye, A. D. (2011). Sustainable Urbanization: Issues and Challenges for Effective Urban Governance in Nigeria. Sustainable Development, 4(6), 211-224.

Mabogunje, A. L. (2005, December 5): Housing Sector Reform: The Journey So Far. The Guardian, 33.

Mabogunje, A, L. (2008): “The Challenges of Mobility within Nigeria's Emerging Megacities", Keynote Address delivered at the Maiden Annual National Conference on Public Transportation organized by the Lagos Metropolitan Area Authority (LAMATA), May 6-8, 2008.

Map of World (2012) Political Map of Nigeria. www.mapofworld.com/Nigeriapolitical-map.html Accessed on 19/12/12

Maruani, T., \& Amit-Cohen. (2007). Open Space Planning Models: A Review of Approaches and Method. Landscape and Urban Planning, 81(1-13).

Michael, K. (2007): Dictionary of Sports Science and Medicine, UK, Oxford University Press.

Montgomery, M. R., Richard Stren, Barney Cohen and Holly E. Reed (eds) (2004): Cities Transformed: Demographic Changes and its Implication in Developing World, London, Earthscan, $529 \mathrm{pp}$

Nicholas, C. B and Carlos, A. T. (2002): Globalization and Education: An Introduction, Routledge Publishers.

Oduwaye, L. (2009). Challenges of Sustainable Physical Planning and Development in 
Metropolitan Lagos. Sustainable Development, 2(1), 159-171.

Ogoko, O. and Albert, O. M. (2006): Igbo Moral-Order in a Dysfunctional Society and Kants Imperatives, Journal on Nigerian Languages and Culture, 8(1).

Ogu, V. I. (2010). Evolutionary Dynamics of Urban Land Use Planning and Environmental Sustainability in Nigeria. Planning Perspectives, 14(4), 347-368.

Okolo, N., \& Okolie, A. O. (2010). Revitalizing Urban Public Spaces in Nigeria through Vegetative Enclaves. Environmental Management and Safety, 1(1), 124-130.

Olajuyigbe, A. E., \& Rotawa, O. O. (2011). Optimizing Physical Planning in the Developing Countries- A case Study of Ondo State, Nigeria. Sustainable Development, 4(4), 202-209.

Olanrewaju, D. O. (2004): Town Planning: A Veritable Means for Poverty Reduction, Inaugural Lecture, Series 38, Federal University of Technology, Akure, 2004, 23.

Olokor, F (2012) Nigeria's Population Stands at 167 Million. Retrieved from www.punch.com/news/nigerias-population Accessed on 19/12/12

Olotuah, O. A., \& Bobadoye, S. A. (2009). Sustainable Housing Provision for the Urban Poor: A Review of Public Sector Intervention in Nigeria. The Built and Human Environment Review, 2, 51-63.

Olujimi, J. A. B. (2011). From Rural to Urban: The Nigerian Physical Planning Dilemma. Akure: Federal University of Technology, Akure.

Omuta, G. E. D. (2006). Environmental Planning, Administration and Management in Nigerian Cities: the Example of Benin City. Public Administration and Development, $8(1), 1-14$.

Quezon City Government (2002): Quezon City Quality Management for a Quality City: The Belmonte Administration Year 1, Quezon City.

Santrock, J.W. (2007): A Tropic Approach to Life-span Development, New York, McGraw Hill.

Serageldin, I. (1997): “ Saving the Public's Cultural Heritage in Cities of the Developing World" The Urban Age, 4(4).

Shilling, C. (2007): Embodying Sociology: Retrospect, Progress and Prospects, The Sociological Review, Blackwell Publishing Ltd.

Sillars, M. and Gronbeck, B. (2001): Communication Criticism: Rhetoric, Social Codes, Cultural Studies, Prospect Heights, IL; Waveland Press Inc.

Stern, P. C. (2000a): New Environmental Theories: Toward a Coherent Theory of Environmental Significant Behavior, Journal of Social Issues, 56(3), 407-424.

Taiwo, D. S. and Busari, L. (1997): "preparation of Realistic and Implementable Strategy Action for Sustainable Cities through the Participatory Planning Approach in Environmental planning and Management Process: A Case study of Sustainable Ibadan Project" A paper Presented at Annual Conference of Nigerian Institute of Town Planners (NITP), October 29th $-31^{\text {st }}, 1997$.

Tisdale, H. (2012). The Process of Urbanization. Retrieved from http://heinonline.org Accessed on $7 / 10 / 12$

Walter, D. (2007). Designing Community, Character, Master Plan and Form, Oxford: Based Code. 
Williams, R. A. (2000). Environmental Planning for Sustainable Development. Paper presented at the Caribbean Water and Waste Water Association, 9th Annual Conference and Exhibition, 2-6 October, 2000, Chaguaramas, Trinidad.

World Bank (2011) Population, Nigeria. Retrieved from www.worldbank.org . Accessed on $20 / 12 / 2012$ 